\title{
Socio-Economic Impact Mechanism of Ecosystem Services Value, a PCA-GWR Approach
}

\author{
Zhenya Zhu ${ }^{1,2 *}$, Binbin $\mathrm{Li}^{3}$, Yongjun $\mathrm{Zhao}^{3}$, Zhengyuan Zhao ${ }^{4}$, Lihua Chen ${ }^{1}$ \\ ${ }^{1}$ College of Soil and Water Conservation, Beijing Forestry University, Beijing,China \\ ${ }^{2}$ Changjiang Water Resources Protection Institute, Wuhan, China \\ ${ }^{3}$ Monitoring Center of Soil and Water Conservation, Ministry of Water Resources, Beijing,China \\ ${ }^{4}$ School of Nature Conservation, Beijing Forestry University, Beijing, China
}

Received: 14 March 2020

Accepted: 18 April 2020

\begin{abstract}
This paper comprehensively used three methods to explore the global and local impact mechanism of socioeconomic on ecosystem services value in Beijing-Tianjin-Hebei region, which included principal component analysis (PAC), ordinary least square (OLS) and geographic weighted regression (GWR). The results suggested that, the primary industry related factors were the main socioeconomic factors, while factors such as the second industry, the third industry, the fiscal revenue and so on, had little effect on it. Socioeconomic factors can affect or change the value of ecosystem services to a certain extent. The comprehensive factor of primary industry had a negative effect, and the negative effect of the total population factor was weaker than the comprehensive factor, meanwhile, the effect of the simplification factor of the primary industry was positive or negative. The local model of a PCA-GWR can better solve the spatial non-stationarity of the dependent and the independent variables, and the local model was better than the global model of OLS and PCA-OLS. A standard GWR model can be further improved to reflect the local differences of the impact mechanism in more detail.
\end{abstract}

Keywords: ecosystem services value, PCA-GWR, socio-economic factors, impact mechanism, Beijing-Tianjin-Hebei region

\section{Introduction}

Ecosystem services (ES) are broadly defined as the benefits obtained directly or indirectly by humans from ecosystems and are often distinguished as provisioning, regulating, cultural, and supporting services [1]. Ecosystem services support human wellbeing in many ways, providing essential sources of nutrition and

*e-mail: zhenya_zhu@126.com materials, regulating and maintaining global systems and enhancing our quality of life [1-3]. In recent years, more and more scholars have paid attention to the theme of ecological service value. As the population expands and energy demands increase, terrestrial ecosystems face increasing effects of human activity $[4,5]$. Human activities, especially land use and land cover change, impact and even alter the provision of ecosystem services $[1,6,7]$. Conflicts between ecosystems and human activities can make the ecological environment vulnerable, leading to a series of ecological degradation problems, such as soil erosion, land degradation, 
desertification and even desertification [8]. The rapid development of urbanization and the resulting population aggregation and land use change are considered to be one of the main reasons for the decline of regional ecosystem services [9, 10].

Although the utilization of ecosystem services knowledge in decision-making is increasingly being promoted by academics and policy makers, its actual uptake in land use management remains largely undetermined [11-13]. Many studies have analyzed the relationship between landscape characteristics or land use and ecosystem services [14-17]. When we explore the landscape features that underpin ecosystem services, it is difficult to link ecosystem services to specific causal factors because there is still a lack of clarity of which variables contribute to the supply of ecosystem services [18-20]. Socioeconomic factors affected the ecosystem services supply by impacting the quantity and quality of ecological facilities and ecological management measures, meanwhile, socioeconomic factors impacted ecosystem services demand [21]. Thus, identification of best-practice management directives in the face of climate change is challenging and requires consideration of socioeconomic aspects [22]. It is necessary to explore various influencing factors and influencing mechanisms of the value of ecological services, including socioeconomic factors reflecting human activities. Thus, identifying the drivers of change provides an opportunity to make the link between ecosystem services, policy making and land management.

In addition, current studies have paid more attention to the quantification of ecosystem services, while lacked the exploration of the driving forces of ecosystem services change [23]. Qualitative analysis of ecosystem driving forces is very common, but quantitative analysis is relatively few. Quantitative research often used traditional statistical analysis, RDA (redundancy analysis) [24], LMDI (logarithmic mean divisiona Index) [25] and other methods, which are essentially global methods. Social-ecological systems are complex, dynamic systems with strong interdependencies between their ecological components and the social actors that depend upon and shape them [26]. Therefore, the multi-collinearity between socialeconomic factors need to be considered. One of the new methods for achieving higher accuracy in spatial analysis is the GWR method, which is highly effective when a spatial correlation exists between independent variables [27]. The study found that the bandwidth sensitivity of different kernel functions was different, and the change of bandwidth had a great influence on the result [28]. Therefore, the difference between GWR can be reflected by the kernel function and bandwidth. Fixed and adaptive kernel functions are two general ways to construct a bandwidth, where an adaptive function adjusts the window catchments for the density of data locations and a fixed function does not [29, 30].
This paper took 167 districts and counties in Beijing-Tianjin-Hebei region as research objects, and 18 socioeconomic factors were selected, as well as four ecosystem service value indicators. PCA was used to eliminate the multi-collinearity of independent variables, so the global model of PCA-OLS was established. Then a local model of a PCA-GWR was established by using GWR method. Therefore, the socioeconomic impact mechanism of the ecosystem services value was systematically explored.

\section{Material and Methods}

\section{Data and Processing}

The socioeconomic data came from Beijing Statistical Yearbook, Tianjin Statistical Yearbook, Hebei Economic Yearbook, Beijing Regional Statistical Yearbook, Hebei Rural Statistical Yearbook and New Hebei 50 Years., as well as Tangshan Statistical Yearbook, Handan Statistical Yearbook, Chuzhou Statistical Yearbook, Qinhuangdao Statistical Yearbook, Xingtai Statistical Yearbook, Chengde Statistical Yearbook, Baoding Economic Statistics Yearbook, Langfang Economic Statistics Yearbook, Hengshui Statistical Yearbook, Zhangjiakou Economic Yearbook and Shijiazhuang Statistical Yearbook. The socioeconomic factors in the region were shown in Table 1

Ecosystem services value included Z1 (total ecosystem services value), Z2 (ecosystem services value per unit area), Z3 (ecosystem services value per capita), and Z4 (ecosystem services value per GDP), which were derived from author's previous research results [31]. Because the area of each research unit was different, the socioeconomic factors cannot scientifically reflect the difference in human activity intensity. The socioeconomic data per unit area can be used to reflect this difference. The post-process socioeconomic factor was Yi'. In the spss22, a preliminary regression analysis were carried out with four dependent variables and the processed socioeconomic factors, and the regression coefficient R2 for Z2 was $66.4 \%$, and severe multicollinearity existed between socioeconomic variables. The regression coefficients were not significant, and the Pearson coefficient between Z2 and Y13', Y3', Y5', Y6', Y7', Y14', Y1' were large. PCA was used to eliminate the multicollinearity of the above variables (without rotation), and then the extracted principal components were used to create the global and local model.

\section{Principal Component Analysis}

PCA is a statistical technique that finds a set of orthogonal low-dimensional basis functions to represent an ensemble of high-dimensional data describing an undesirably complex system [32-34]. PCA used the 
Table 1. The indicators of socio-economic factors in the region.

\begin{tabular}{|c|c|c|c|}
\hline Factors & Meaning & Factors & Meaning \\
\hline Y1 & Year-end total population/10000 persons & Y10 & Total retail sales of consumer goods/10000 yuan \\
\hline Y2 & Urban population/10000 persons & Y11 & $\begin{array}{c}\text { General public budget revenue/ } \\
10000 \text { yuan }\end{array}$ \\
\hline Y3 & Rural population/10000 persons & Y12 & General public budget expenditure/10000 yuan \\
\hline Y4 & Persons employed in various units/person & Y13 & Total grain output/ton \\
\hline Y5 & Number of ruralemployees/person & Y14 & Total meat output/ton \\
\hline Y6 & $\begin{array}{c}\text { Agriculture,forestry, animal husbandry and fishery/ } \\
\text { person }\end{array}$ & Y15 & Industrial enterprises above designated size/unit \\
\hline Y7 & Primary industry/10000 yuan & Y16 & $\begin{array}{c}\text { Gross output value of industry above designated } \\
\text { size/10000 yuan }\end{array}$ \\
\hline Y8 & Secondary industry/10000 yuan & Y17 & $\begin{array}{c}\text { Investment of urban fixed assets/ } \\
10000 \text { yuan }\end{array}$ \\
\hline Y9 & Tertiary industry/10000 yuan & Y18 & Investment in non-urban fixed assets/10000 yuan \\
\hline
\end{tabular}

Note: Y1-Y3 are population factors, Y4-Y6 are employment factors, Y7-Y9 are economic factors, Y10 is commercial factor, $\mathrm{Y} 11, \mathrm{Y} 12$ are financial factors, $\mathrm{Y} 13, \mathrm{Y} 14$ are agricultural factors, $\mathrm{Y} 15, \mathrm{Y} 16$ are industrial factors, $\mathrm{Y} 17, \mathrm{Y} 18$ represent fixed asset investment.

idea of dimensionality reduction to transform multiple variables into a few independent variables that were linearly combined with the original variables, so that the information of the original variables can be extracted mostly.

$\mathrm{K} 1$ is the principal component index formed by the first linear combination of the original variables, namely $\mathrm{K} 1=\mathrm{a} 11 \mathrm{X} 1+\mathrm{a} 21 \mathrm{X} 2+\ldots+\mathrm{ap} 1 \mathrm{Xp}$. According to the mathematical knowledge, the information of the principal component can be measured by the variance, and the magnitude of the variance represented the size of the information. In actual operation, the first principal component $\mathrm{K} 1$ contained the largest amount of information. If $\mathrm{K} 1 \mathrm{did}$ not reflect the information of the original variables, the second principal component $\mathrm{K} 2$ needed to be selected. In order to effectively reflect the original information, $\mathrm{K} 2$ and $\mathrm{K} 1$ were independent from each other, that was, $\operatorname{Cov}(\mathrm{K} 1, \mathrm{~K} 2)=0$, so $\mathrm{K} 2$ was the comprehensive variable with the largest variance except $\mathrm{K} 1$, called the second principal component. Extracting $\mathrm{K} 1, \mathrm{~K} 2 \ldots . . ., \mathrm{Km}$ in order, which were the first, second, ..., $\mathrm{m}$-th principal component of the original variables.

$$
\left\{\begin{array}{c}
K_{1}=a_{11} X_{1}+a_{12} X_{2}+\cdots+a_{1 p} X_{p} \\
K_{m}=a_{m 1} X_{1}+a_{m 2} X_{2}+\cdots+a_{m p} X_{p}
\end{array}\right.
$$

According to the above analysis, the main work of PCA was to determine the expression of $\mathrm{Ki}$ ( $\mathrm{i}=1,2, \ldots \ldots, \mathrm{m})$ that was to determine the combination coefficient aij of the original variables; the second is the principal component load $\mathrm{p}(\mathrm{Zk}, \mathrm{Xi})=\sqrt{\lambda_{k}} a_{k i}(\mathrm{i}=$ $1,2, \ldots \ldots, \mathrm{p} ; \mathrm{k}=1,2, \ldots \ldots, \mathrm{m})$ that calculates the degree of correlation between the principal component and the original variable $\mathrm{Xj}$.

\section{Geographically Weighted Regression}

Based on the regression of spatial coefficient of variation, GWR model was proposed using the idea of local smoothness [35, 36]. GWR was an extension of the least-squares regression, that was, the geographic location information on the sample points was introduced in the regression parameters, and the formula was:

$$
\begin{gathered}
\mathrm{y}_{\mathrm{i}}=\beta_{\mathrm{i} 0}\left(\mathrm{u}_{\mathrm{i}}, \mathrm{v}_{\mathrm{i}}\right)+\sum_{\mathrm{k}=1}^{\mathrm{p}} \beta_{\mathrm{ik}}\left(\mathrm{u}_{\mathrm{i}}, \mathrm{v}_{\mathrm{i}}\right) \mathrm{x}_{\mathrm{ik}}+\varepsilon_{\mathrm{i}} \\
\mathrm{i}=1,2, \ldots, \mathrm{n}
\end{gathered}
$$

...where yi was the dependent variable of point $i$, xik was the explanatory variable of point $i$, and (ui, vi) is the geographical position information of the point $i$, $\beta_{\mathrm{i} 0}(\mathrm{ui}, \mathrm{vi}), \beta_{\mathrm{ik}}$ (ui, vi) was the constant term of point i and $\mathrm{k}$-th independent variable coefficient, respectively, and \&i was an independent and identically distributed error term, usually obeying the distribution of $\mathrm{N}\left(0, \sigma^{2}\right)$.

Create a spatial data file, which included the number of each unit, the longitude $\mathrm{Xi}$ of the centroid, the latitude Yi of the centroid, the standardized independent variable $\mathrm{K} 1, \mathrm{~K} 2, \mathrm{~K} 3$, and the standardized $\mathrm{Z} 2$. The data file was imported into the GWR 4.0. The Gaussian GWR model was established as follows:

$$
\begin{aligned}
Z Z 2_{i} & =\beta_{0}\left(X_{i}, Y_{i}\right)+\beta_{1}\left(X_{i}, Y_{i}\right) K 1_{i}+\beta_{2}\left(X_{i}, Y_{i}\right) K 2_{i} \\
+ & \beta_{3}\left(X_{i}, Y_{i}\right) K 3_{i}+\varepsilon_{i} \quad i=1,2, \ldots, 167
\end{aligned}
$$

...where $\mathrm{Xi}$ and $\mathrm{Yi}$ were the projection coordinates of the centroid of unit $\mathrm{i}$, and $\mathrm{K} 1 \mathrm{i}, \mathrm{K} 2 \mathrm{i}$ and $\mathrm{K} 3 \mathrm{i}$ were the first, second and third principal component scores of unit $i$, respectively. 


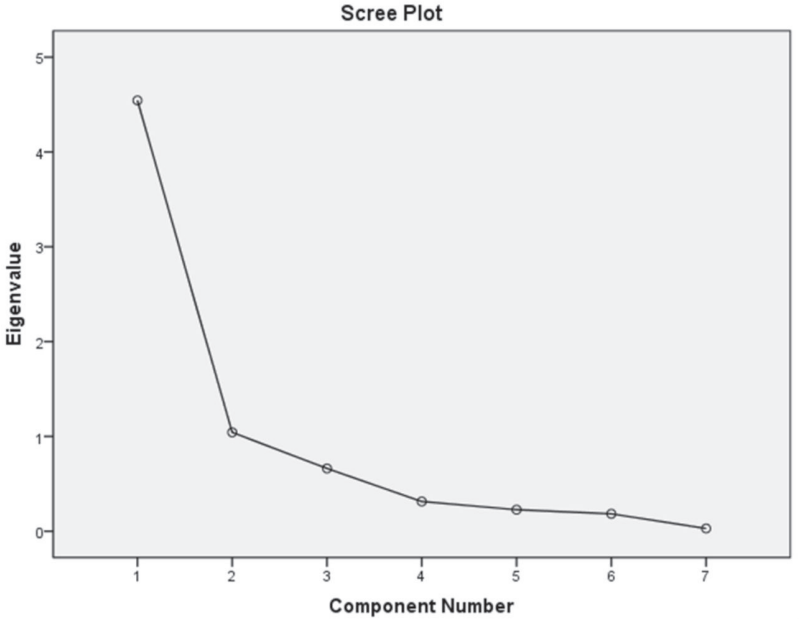

Fig. 1. Rock fragments of PCA based on socio-economic factors.

In GWR model, there are three methods for estimating the bandwidth parameters of the weight function: nearest neighbor bandwidth parameter method, $\mathrm{CV}$ (cross validation) and AIC (Akaike information criterion) [37]. Compared with $\mathrm{CV}$, AIC was easier to avoid over-fitting problems, so AIC method was used more in the actual modeling process. Adaptive core and golden section search method were used to fit model, and the local coefficients were estimated by the nearest 48 units, the minimum AICc (AIC for small sample deviation correction) was 157.306.

\section{Results and Discussion}

The Global Mechanism of Socioeconomic Factors

\section{Output of PCA-OLS Model}

At the 0.05 significance level, the KMO (KaiserMeyer-Olkin) and Bartlett's Test was close to 1 , the original hypothesis that the correlation coefficient matrix was a unit matrix was rejected, indicating that there was a correlation between variables, so it was suitable for factor analysis. The extraction of each factor by the common factor variance was greater than 0.8 , indicating that the commonality of the variables was high, and the information about the variables can be extracted mostly, and the results of the PCA were effective. After extracting three principal components, the cumulative square sum of the extracted loads was $89.26 \%$, and the extraction effect was ideal.

The gravel diagram of principal components was shown in Fig. 1. Except for the first three factors, the slope of the other factors was smaller, and the first three factors were the main components.

The component matrix and eigenvector were shown as Table 2. The feature vector can be obtained, that was the component matrix was divided by the corresponding eigenvalue. Three eigenvectors were defined because there are three factors.

According to the eigenvector matrix, the calculation formulas of the three principal components can be written. Population, employment and economy played a balanced role in $\mathrm{K} 1$, which comprehensively reflected the situation of the primary industry, so it can be called the primary industry comprehensive factor; Y1 played a greater role in $\mathrm{K} 2$, so it can be called the total population factor; Y7, Y1, Y6, Y14 played a similar role in $\mathrm{K} 3$, and it also reflected the primary industry in a more comprehensive way. However, compared with the information on $\mathrm{K} 1, \mathrm{~K} 3$ was called the primary industry simplification factor.

The results of the PCA-GWR showed that, K1 was selected in the model, and the adjusted $\mathrm{R}$ square was 0.552 , and the regression fit was better. In the analysis of variance table, $\mathrm{F}=205.192>\mathrm{F} 0.05$ (m,n-m-1) $=\mathrm{F} 0.05(1,165)=3.92$, that was, the regression equation was significant at the 0.05 significance level, and the established OLS model was statistically significant. In the collinear diagnosis, the tolerance of K1 was greater than 0.1, and the VIF (Variance Inflation Factors) was less than 10, and K1 did not have multiple

Table 2. Component Matrix and Eigenvector.

\begin{tabular}{|c|c|c|c|c|c|c|}
\hline & \multicolumn{3}{|c|}{ Component Matrix a } & \multicolumn{3}{|c|}{ Eigenvector } \\
\hline & \multicolumn{6}{|c|}{ Component } \\
\hline & 1 & 2 & 3 & 1 & 2 & 3 \\
\hline Y1' & 0.428 & 0.793 & 0.406 & 0.201 & 0.776 & 0.499 \\
\hline Y3' & 0.948 & 0.113 & -0.151 & 0.445 & 0.111 & -0.186 \\
\hline Y5 & 0.942 & 0.197 & -0.118 & 0.442 & 0.193 & -0.145 \\
\hline Y6' & 0.841 & 0.096 & -0.351 & 0.395 & 0.094 & -0.431 \\
\hline Y7' & 0.761 & -0.28 & 0.432 & 0.357 & -0.274 & 0.531 \\
\hline Y13' & 0.88 & -0.163 & -0.212 & 0.413 & -0.159 & -0.26 \\
\hline Y14' & 0.717 & -0.498 & 0.324 & 0.336 & -0.488 & 0.398 \\
\hline
\end{tabular}

Extraction Method: Principal Component Analysis. a. 3 components extracted. 
collinearity. From this, PCA-OLS equation can be established.

\section{Analysis of the Global Impact Mechanism}

Socioeconomic related to the primary industry had a negative impact on Z2, such as Y13', Y3', Y5', Y6', Y7', Y14'; and factors related to the secondary industry, tertiary industry, fiscal revenue, such as Y2 ', Y4', Y8', Y9', Y15', Y16', Y17', Y18', Y10', Y11', Y12', had less effect on the Z2. The goodness of fit test based on PCA-OLS was not ideal. After eliminating the multicollinearity, it can explain the variation of $\mathrm{Z} 2$ by $55.4 \%$. Considering the influence of DOF, $55.2 \%$ of the variance can be explained. And socioeconomic factors can only affect or change the ecosystem services value in the region to a certain extent.

There were some spatial and temporal heterogeneity in socioeconomic factors, the global model of PCAOLS cannot deal with an imbalance problem well, and it was necessary to further establish a local model of socioeconomic factors.

\section{The Local Impact Mechanism of Socioeconomic Factors}

\section{Testing the Fitting Effect of PCA-GWR}

The analysis of variance and the variability test results were shown in Table 3 and Table 4.
The test results showed that the GWR model improved the effect of the global model, the GWR model solved the problem of spatial non-stationarity, and the fitting effect of the GWR model was better than the global model of OLS.

According to geographical variability tests of local coefficients, the standard deviation of principal component variables were all negative values, indicating that three principal component variables had spatial non-stationary. The fitting results of PCA-OLS and PCA-GWR model were shown in Table 5.

From the comparison of evaluation index, the difference of the AIC and AICc between the two models was much larger than 3, which were 202.8346 and 190.2718, respectively, the PCA-GWR was better than the PCA-OLS model. From the CV value, the PCA-GWR model was also smaller, further indicating that the results of the local model were better. The $\mathrm{R}$-square and the adjusted R-square of the local model were 0.3452 and 0.3291 higher than the global model, respectively. The local model had a great explanatory power for the variation, and the results were very satisfactory. The local model solved the problem of spatial non-stationarity of $\mathrm{Z} 2$ and three principal component factors.

\section{Statistical Analysis of Local Coefficients}

The local model can obtain the local coefficients of each unit. Descriptive statistics for local coefficients

Table 3. Analysis of variance by geographic weighted regression.

\begin{tabular}{|c|c|c|c|c|}
\hline Source & SS & DF & MS & F \\
\hline Global Residuals & 73.649 & 163 & & \\
\hline GWR Improvement & 57.296 & 31.776 & 1.803 & 14.46992 \\
\hline GWR Residuals & 16.352 & 131.224 & 0.125 & \\
\hline
\end{tabular}

Table 4. Geographical variability tests of local coefficients.

\begin{tabular}{|c|c|c|c|c|}
\hline Variable & F & \multicolumn{2}{|c|}{ DOF for F test } & DIFF of Criterion \\
\hline Intercept & 16.67097 & 5.094 & 138.755 & -65.1794 \\
\hline K1 & 15.17711 & 5.067 & 138.755 & -59.1609 \\
\hline K2 & 2.754103 & 5.238 & 138.755 & -1.56227 \\
\hline K3 & 3.210676 & 4.896 & 138.755 & -3.9089 \\
\hline
\end{tabular}

Note: positive value of diff-Criterion (AICc, AIC, BIC/MDL or CV) suggests no spatial variability in terms of model selection criteria. F test: in case of no spatial variability, the F statistics follows the F distribution of DOF for F test.

Table 5. The fitting results of OLS and GWR model.

\begin{tabular}{|c|c|c|c|c|c|c|}
\hline Model & AIC & AICc & BIC/MDL & CV & $\begin{array}{c}\text { R } \\
\text { square }\end{array}$ & $\begin{array}{c}\text { Adjusted } \\
\text { R square }\end{array}$ \\
\hline PCA-OLS & 347.20493 & 347.5776 & 362.794899 & 0.507451 & 0.556332 & 0.545378 \\
\hline PCA-GWR & 144.37031 & 157.30581 & 235.555173 & 0.439754 & 0.901492 & 0.874429 \\
\hline
\end{tabular}


Table 6. Summary statistics for local coefficients.

\begin{tabular}{|c|c|c|c|c|c|c|c|}
\hline Variable & Mean & STD & Min & Lwr Quartile & Median & Upr Quartile & Max \\
\hline Intercept & -0.18311 & 0.315514 & -0.70708 & $\mathbf{- 0 . 5 1 0 1 4}$ & -0.10328 & $\mathbf{0 . 0 8 2 7 2 9}$ & 0.45852 \\
\hline K1 & -0.3217 & 0.222124 & -0.74189 & $\mathbf{- 0 . 4 2 7 9 2}$ & -0.27356 & $\mathbf{- 0 . 1 4 6 2 3}$ & -0.01777 \\
\hline K2 & -0.02905 & 0.156493 & -0.392118 & $\mathbf{- 0 . 1 2 8 5 5}$ & -0.05004 & $\mathbf{0 . 0 4 2 9 6 1}$ & 0.380216 \\
\hline K3 & 0.023199 & 0.171733 & -0.541195 & $\mathbf{- 0 . 0 5 9 1 1}$ & 0.013717 & $\mathbf{0 . 1 0 9 6 8 5}$ & 0.535023 \\
\hline
\end{tabular}

of the three principal components were shown in Table 6.

By observing the inclusion relationship between the upper and lower quartiles of the local coefficient and the \pm 1 standard deviation of global coefficients, this paper analyzed whether the distribution of the principal components had spatial non-stationarity. The upper and lower quartile range of K1's local coefficients were $[-0.42792,-0.14623]$, the standard deviation range of global coefficients were [-0.373739, -0.324789]; The upper and lower quartile range of K2's local coefficients were $[-0.12855,0.042961]$, the standard deviation range of global coefficients were [-0.066678, 0.035526]; The upper and lower quartile range of K3's local coefficients and the standard deviation of global coefficients were [-0.05911, 0.109685] and [-0.012063, 0.116263], respectively. The range of \pm 1 standard deviation of the global coefficients cannot contain the range of the upper and lower quartiles of the local coefficients, the local coefficients of K1, K2 and K3 all had spatial nonstationarity to some extent.

The distribution of local coefficients revealed the difference in the effects of principal components. In the whole region, there was a negative correlation between
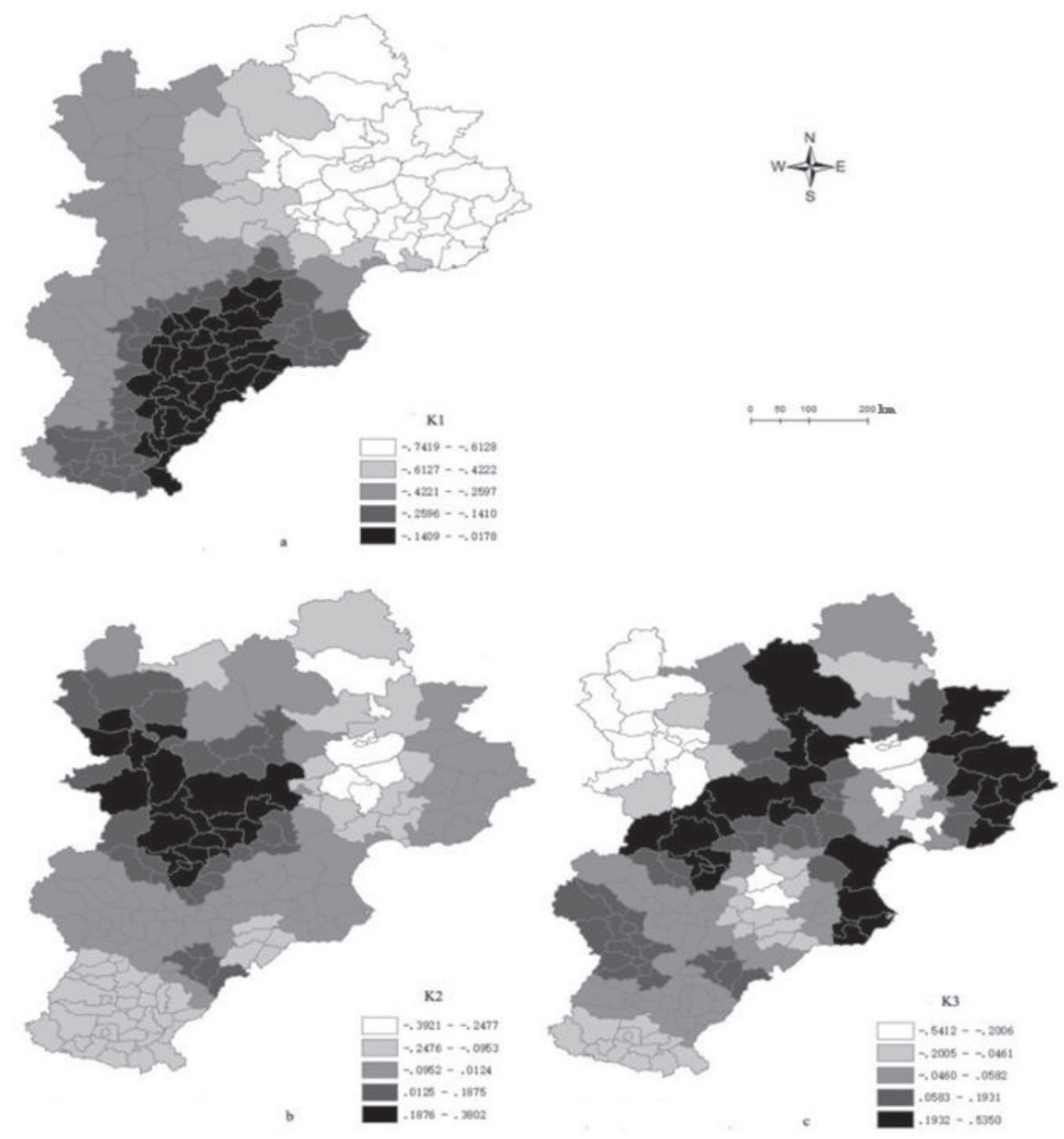

Fig. 2. Local regression coefficients distribution. 
$\mathrm{K} 1$ and $\mathrm{Z} 2$, and the negative effect of the first principal component was very significant; the negative correlation between $\mathrm{K} 2$ and $\mathrm{Z} 2$ was dominant, the negative effect of $\mathrm{K} 2$ was more obvious, but weaker than $\mathrm{K} 1$; while K3 had a positive and negative effect . The units with negative coefficients of K1 and K2 were 167 and 115, accounting for $100.00 \%$ and $68.86 \%$, respectively; the units with positive and negative coefficients of K3 were 93 (accounting for 55.69\%) and 74 (accounting for $44.31 \%$ ), the absolute values of positive and negative coefficients were very close, so in the whole region, Z2 was affected by the positive and negative effects of $\mathrm{K} 3$.

\section{Spatial Distribution of Local Regression Coefficients}

Visualization analysis of local coefficients of three components in ArcGIS 10.2, the distribution of local coefficients were showed as Fig. 2.

The most significant negative effect of $\mathrm{K} 1$ was located in Chengde, Qinhuangdao and Tangshan in the north, especially in the northeast, while most of the southeastern part of the region had less negative effects; The negative effect of K1 was gradually weakened from the northeastern to the northwest and then to the southwest of the region. The negative effect of K2 was mainly located in a small part of Chengde and Tangshan in the northeast, in the northwest of the region, such as Zhangjiakou, Beijing and Baoding, there was a positive effect; the positive effect of K2 gradually weakened from the Midwest to the south and then to northeast. The effect of K3 was more complicated: the regions with more positive effects were located in Chengde, Beijing, Baoding, and parts of Cangzhou and Qinhuangdao, the areas with negative effects were located in Zhangjiakou, Tangshan and Langfang, the positive and negative effects of the northern part of the region were more obvious, but the effects were relatively scattered. It was more obvious that the spatial heterogeneity of the interaction between $\mathrm{K} 2$ and $\mathrm{K} 3$ on $\mathrm{Z} 2$, in addition to the complexity of the socioeconomic factors, and the information extracted by PCA had a declining explanatory power for the dependent variables.

\section{Discussion}

\section{Selection of Socioeconomic Factors}

Previous studies had focused on the impact of socioeconomic factors on the ecosystem services value. Some scholars have confirmed the impact of urbanization on the ecosystem services value [38-40], Urbanization indicators focus more on the internal situation of the city. Even in the highly urbanized Beijing-Tianjin-Hebei region, the proportion of nonurban construction areas is still very large, and it is obviously unscientific to ignore the relevant factors of the primary industry. Some scholars choose individual factors to study the interaction between socioeconomic factors and ecosystem services value [41, 42]. In these studies, the choice of socioeconomic factors was arbitrary. It was assumed that there was a relationship between the selected factors and ecosystem services value. In this paper, the socioeconomic factors were very comprehensive, including population, employment, economy, commerce, finance, agriculture, industry, and fixed asset investment. Seven factors were selected by correlation analysis, and then the PCA method was used to extract the main information about these factors. This not only avoided the arbitrariness of factor selection, but also eliminated the multi-collinearity between socialeconomic factors. The data used to be relatively easy to obtain from the statistical yearbook, which made these methods higher operability and suitability.

\section{Improvement of GWR Model}

GWR is an exploratory technique for examining process non-stationarity in data relationships, which can reflect the local differences of social-economic impact mechanism in different research units, and it is not possible for the global model. But a standard GWR may underestimate localized spatial heterogeneity where it is strongly present, hyper-local GWR can provide an alternative, complementary and more nuanced interpretation of localized regression [43]. GWR model cannot exclude multi-collinearity among factors, Bayesian method can solve this problem [44], thus the mechanism of seven factors can be analyzed at the same time, and the scalability of the model can be enhanced. Limited by the least squares criterion, the parameter estimation of GWR will produce outliers, and the local linear geographic weighted regression can automatically reduce the influence of outliers [45]. The general GWR model does not consider the time characteristics, so it needs to be improved in application. Some scholars put forward Geographically and temporally weighted regression (GTWR) model [46], which is closer to the real situation, and the regression results are better than standard GWR[47]. Thus, an improved method can be implemented at low administrative levels to get detailed differences of the impact mechanism with ecosystem services value.

\section{Conclusions}

This paper comprehensively used PAC, OLS and GWR to explore the global and local impact mechanism of socioeconomic on ecosystem services value in Beijing-Tianjin-Hebei region. The results suggested that, the factors related to the primary industry were the main socioeconomic factors, while the socioeconomic factors such as the secondary industry, the tertiary industry, and fiscal revenue and so on, had little effect on it. Socioeconomic factors can affect or change the value of ecosystem services to a certain extent. The comprehensive factor of primary industry had 
a negative effect, and the negative effect of the total population factor was weaker than the comprehensive factor, meanwhile, the effect of the simplification factor of the primary industry was positive or negative. The local PCA-GWR model better solved the spatial nonstationarity of independent and dependent variables, and it was superior to the global models of OLS and PCA-OLS. A standard GWR model can be further improved to reflect the local differences of the impact mechanism in more detail.

\section{Acknowledgments}

The authors would like to thank the anonymous reviewers for comments on earlier versions of this manuscript. This research was funded by Tsinghua Rural Studies Ph.D. Scholarship (NO.201701), playing the role in the further improvement of the paper, and in the decision to submit the article for publication.

\section{Conflict of Interest}

The authors declare no conflict of interest.

\section{References}

1. MEA. Millennium ecosystem assessment synthesis. Island Press: Washington DC, 2005

2. COSTANZA R., D'ARGE R., DE GROOT R., FARBER S., GRASSO M., HANNON B., LIMBURG K., NAEEM S., O'NEILL R.V., PARUELO J., RASKIN R.G., SUTTON P., VAN DEN BELT M. The value of the world's ecosystem services and natural capital (Reprinted from Nature, vol 387, pg 253, 1997). Ecological Economics 25, (1), 3, 1998.

3. MAES J., LIQUETE C., TELLER A., ERHARD M., PARACCHINI M.L., BARREDO J.I., GRIZZETTI B., CARDOSO A., SOMMA F., PETERSEN J.E., MEINER A., GELABERT E.R., ZAL N., KRISTENSEN P., BASTRUP-BIRK A., BIALA K., PIRODDI C., EGOH B., DEGEORGES P., FIORINA C., SANTOS-MARTIN F., NARUSEVICIUS V., VERBOVEN J., PEREIRA H.M., BENGTSSON J., GOCHEVA K., MARTA-PEDROSO C., SNALL T., ESTREGUIL C., SAN-MIGUEL-AYANZ J., PEREZ-SOBA M., GRET-REGAMEY A., LILLEBO A.I., MALAK D.A.,CONDE S., MOEN J., CZUCZ B., DRAKOU E.G., ZULIAN G., LAVALLE C. An indicator framework for assessing ecosystem services in support of the EU Biodiversity Strategy to 2020. Ecosystem Services 17, 14, 2016.

4. LI T., LI W., QIAN Z. Variations in ecosystem service value in response to land use changes in Shenzhen. Ecological Economics 69 (7), 1427, 2010.

5. TSOU J.Y., GAO Y., ZHANG Y., SUN G., REN J., LI Y. Evaluating Urban Land Carrying Capacity Based on the Ecological Sensitivity Analysis: A Case Study in Hangzhou, China. Remote Sensing 9 (6), 2017.

6. TOLESSA T., SENBETA F., KIDANE M. The impact of land use/land cover change on ecosystem services in the central highlands of Ethiopia. Ecosystem Services 23, 47, 2017.

7. FU B. Ecosystem service and ecological security. Higher Education Press: Beijing, 2013.

8. CHEN B., ZHANG X., TAO J., WU J., WANG J., SHI P., ZHANG Y., YU C. The impact of climate change and anthropogenic activities on alpine grassland over the Qinghai-Tibet Plateau. Agricultural and Forest Meteorology 189, 11, 2014.

9. ZANG S., WU C., LIU H., NA X. Impact of urbanization on natural ecosystem service values: a comparative study. Environmental Monitoring and Assessment 179 (1-4), 575, 2011.

10. MANES F., MARANDO F., CAPOTORTI G., BLASI C., SALVATORI E., FUSARO L., CIANCARELLA L., MIRCEA M., MARCHETTI M., CHIRICI G., MUNAFO M. Regulating Ecosystem Services of forests in ten Italian Metropolitan Cities: Air quality improvement by PM10 and O-3 removal. Ecological Indicators 67, 425, 2016.

11. MARTINEZ-HARMS M.J., BRYAN B.A., BALVANERA P., LAW E.A., RHODES J.R., POSSINGHAM H.P., WILSON K.A. Making decisions for managing ecosystem services. Biological Conservation 184, 229, 2015.

12. COWELL R., LENNON M. The utilisation of environmental knowledge in landuse planning: drawing lessons for an ecosystem services approach. Environment and Planning C-Government and Policy 32 (2), 263, 2014.

13. JORDAN A., RUSSEL D.J.E. Embedding the concept of ecosystem services? The utilisation of ecological knowledge in different policy venues. Environment and Planning C: Government and Policy, 32 (2), 1922014.

14. QUETIER F., LAVOREL S., THUILLER W., DAVIES I. Plant-trait-based modeling assessment of ecosystemservice sensitivity to land-use change. Ecological Applications 17 (8), 2377, 2007.

15. NELSON E., SANDER H., HAWTHORNE P., CONTE M., ENNAANAY D., WOLNY S., MANSON S., POLASKY S. Projecting Global Land-Use Change and Its Effect on Ecosystem Service Provision and Biodiversity with Simple Models. Plos One 5 (12), 2010.

16. GRAFIUS D.R., CORSTANJE R., WARREN P.H., EVANS K.L., HANCOCK S., HARRIS J.A. The impact of land use/land cover scale on modelling urban ecosystem services. Landscape Ecology 31 (7), 1509, 2016.

17. CHEN W., CHI G., LI J. The spatial association of ecosystem services with land use and land cover change at the county level in China, 1995-2015. Science of the Total Environment 669, 459, 2019.

18. ANDERSSON E., MCPHEARSON T., KREMER P. GOMEZ-BAGGETHUN E., HAASE D., TUVENDAL M., WURSTER D., Scale and context dependence of ecosystem service providing units. Ecosystem Services 12, 157, 2015.

19. BENNETT E.M., PETERSON G.D., GORDON L.J. Understanding relationships among multiple ecosystem services. Ecology Letters 12 (12), 1394, 2009.

20. MITCHELL M.G.E., SUAREZ-CASTRO A.F., MARTINEZ-HARMS M., MARON M.,MCALPINE C., GASTON K.J., JOHANSEN K., RHODES J.R. Reframing landscape fragmentation's effects on ecosystem services. Trends in Ecology \& Evolution 30 (4), 190, 2015.

21. WILKERSON M.L., MITCHELL M.G.E., SHANAHAN D., WILSON K.A., IVES C.D., LOVELOCK C.E., RHODES J.R. The role of socio-economic factors in planning and managing urban ecosystem services. Ecosystem Services 31, 102, 2018. 
22. SCHEITER S., SCHULTE J., PFEIFFER M., MARTENS C., ERASMUS B.F.N., TWINE W.C. How Does Climate Change Influence the Economic Value of Ecosystem Services in Savanna Rangelands? Ecological Economics 157, 342, 2019.

23. JIANG W. Ecosystem services research in China: A critical review. Ecosystem Services 26, 10, 2017.

24. WU X., LIU S.L., ZHAO S., HOU X.Y., XU J.W., DONG S.K., LIU G.H. Quantification and driving force analysis of ecosystem services supply, demand and balance in China. Science of the Total Environment 652, 1375, 2019.

25. ZHONG S.Z., GENG Y., QIAN Y.Y., CHEN W., PAN H.Y. Analyzing ecosystem services of freshwater lakes and their driving forces: the case of Erhai Lake, China. Environmental Science and Pollution Research 26, (10), 10219, 2019.

26. POGUE S.J., DEARING J.A., EDWARDS M.E., POPPY G.M. Examining change in complex social-ecological systems using multiple long-term records: the New Forest a case study. WIT Transactions on The Built Environment, 168, 273, 2015.

27. FOTHERINGHAM A.S., CHARLTON M.E., BRUNSDON C. Spatial Variations in School Performance: a Local Analysis Using Geographically Weighted Regression. Geographical and Environmental Modelling 5, (1), 43, 2001

28. TENREIRO C. A weighted least-squares cross-validation bandwidth selector for kernel density estimation. Communications in Statistics - Theory and Methods 46, (7), 3438, 2016.

29. WHEELER D.C., PÁEZ A. Geographically weighted regression. In: Fischer M., Getis A. (eds) Handbook of Applied Spatial Analysis. Springer, Berlin, Heidelberg, 2010.

30. FOTHERINGHAM A.S., BRUNSDON C., CHARLTON M. Geographically weighted regression: the analysis of spatially varying relationships. John Wiley \& Son: England, 2003.

31. ZHENYA Z., PUJIN Y., LI R., LIHUA C., XIANCHUN L. Scenario simulation of ecosystem service value based on landscape transformation. Fresenius Environmental Bulletin 26 (11), 6812, 2017.

32. PARENTE A., SUTHERLAND J.C. Principal component analysis of turbulent combustion data: Data pre-processing and manifold sensitivity. Combustion and Flame 160 (2), 340, 2013.

33. COUSSEMENT A., ISAAC B.J., GICQUEL O., PARENTE A. Assessment of different chemistry reduction methods based on principal component analysis: Comparison of the MG-PCA and score-PCA approaches. Combustion and Flame 168, 83, 2016.

34. BIZON K., CONTINILLO G., MANCARUSO E., MEROLA S.S., VAGLIECO B.M. POD-based analysis of combustion images in optically accessible engines. Combustion and Flame 157, (4), 632, 2010.
35. BRUNSDON C., FOTHERINGHAM A.S., CHARLTON M.E. Geographically weighted regression: a method for exploring spatial nonstationarity. Geographical Analysis 28 (4), 281, 1996.

36. FOTHERINGHAM A.S. Trends in quantitative methods I: stressing the local. Progress in Human Geography 21 (1), 88, 1997.

37. CHEN Q., MEI K., DAHLGREN R.A., WANG T., GONG J., ZHANG M. Impacts of land use and population density on seasonal surface water quality using a modified geographically weighted regression. Science of the Total Environment 572, 450, 2016.

38. WAN L.L., YE X.Y., LEE J., LU X.Q., ZHENG L., WU K.Y. Effects of urbanization on ecosystem service values in a mineral resource-based city. Habitat International 46, 54, 2015.

39. LI B.J., CHEN D.X., WU S.H., ZHOU S.L., WANG T.,CHEN H. Spatio-temporal assessment of urbanization impacts on ecosystem services: Case study of Nanjing City, China. Ecological Indicators 71, 416, 2016.

40. ZHOU D.Y., TIAN Y.Y., JIANG G.H. Spatio-temporal investigation of the interactive relationship between urbanization and ecosystem services: Case study of the Jingjinji urban agglomeration, China. Ecological Indicators 95, 152, 2018.

41. SU S.L., LI D.L., HU Y.N., XIAO R., ZHANG Y. Spatially non-stationary response of ecosystem service value changes to urbanization in Shanghai, China. Ecological Indicators 45, 332, 2014.

42. ZHANG Z.M., GAO J.F., FAN X.Y., LAN Y., ZHAO M.S. Response of ecosystem services to socioeconomic development in the Yangtze River Basin, China. Ecological Indicators 72, 481, 2017.

43. COMBER A., WANG Y.Q., LU Y., ZHANG X., HARRIS P. Hyper-local geographically weighted regression: extending GWR through local model selection and local bandwidth optimization. Journal of Spatial Information Science 17, 63, 2018.

44. WHEELER D.C., WALLER L.A. Comparing spatially varying coefficient models: a case study examining violent crime rates and their relationships to alcohol outlets and illegal drug arrests. Journal of Geographical Systems 11, (1), 1, 2009.

45. ZHANG H.G., MEI C.L. Local least absolute deviation estimation of spatially varying coefficient models: robust geographically weighted regression approaches. International Journal of Geographical Information Science 25 (9), 1467, 2011.

46. HUANG B., WU B., BARRY M. Geographically and temporally weighted regression for modeling spatiotemporal variation in house prices. International Journal of Geographical Information Science 24 (3), 383, 2010.

47. FOTHERINGHAM A.S., CRESPO R., YAO J. Geographical and Temporal Weighted Regression (GTWR). Geographical Analysis 47 (4), 431, 2015. 
